\title{
Retinopathy of prematurity in surfactant treated infants
}

\author{
S J A Rankin, T R J Tubman, H L Halliday, S S Johnston
}

\begin{abstract}
Seventy six babies of less than $1500 \mathrm{~g}$ birth weight who had surfactant replacement therapy for severe respiratory distress syndrome were studied to assess the presence and stage of subsequent retinopathy of prematurity (ROP). A control group of 90 babies, matched for birth weight and gestational age, who did not have surfactant therapy were also studied. Threshold ROP or greater was found in $1.7 \%$ of the surfactant group and $7.8 \%$ of the controls. For the babies of less than $1000 \mathrm{~g}$ birth weight $4.0 \%$ of the surfactant babies and $16 \cdot 3 \%$ of the controls reached threshold disease or greater. It is concluded that surfactant therapy is not associated with an increased incidence or severity of severe ROP in this preterm population.
\end{abstract}

Retinopathy of prematurity (ROP) continues to be a potential major handicap for infants surviving neonatal intensive care. Its incidence and severity are greater in preterm infants of less than $1500 \mathrm{~g}$ birth weight or of less than 31 weeks' gestation. Neonatal respiratory distress syndrome (RDS) is due to surfactant deficiency and occurs predominantly in preterm infants of less than 32 weeks' gestation. Pulmonary surfactant is a complex mixture of phospholipids and proteins produced by type II alveolar pneumocytes; deficiency leads to alveolar collapse, ventilation-perfusion abnormalities, and hypoxaemia so that supplemental oxygen must be given to maintain arterial oxygen tension $\left(\mathrm{PaO}_{2}\right)$. Recent studies have shown that administration of exogenous natural surfactant to infants with RDS decreases neonatal mortality by $40 \%$. $^{\prime}$ The administration of exogenous natural surfactant is associated with an acute rise in $\mathrm{PaO}_{2}$. This can be closely monitored by pulse oximetry and the inspired oxygen concentration reduced rapidly to maintain an adequate $\mathrm{PaO}_{2}$ and prevent hyperoxaemia. Following surfactant therapy there is improved gas exchange for at least the first 72 hours of life and subsequently a reduction in neonatal deaths. ${ }^{12}$

We were concerned that because of the increased survival rate of these extremely low birthweight babies associated with the large surge of $\mathrm{PaO}_{2}$ at the time of surfactant delivery that there may be an increased risk of ROP.

Surfactant therapy has only recently been established as routine management in RDS and few data exist about the subsequent eye complications. We decided to study the incidence and severity of ROP in babies treated with surfactant for severe RDS and compare their outcome with that of less ill preterm babies who were not given surfactant. We have gathered ophthalmic data retrospectively from the records of those infants who received surfactant therapy at this institution from 1985-1990.

\section{Materials and methods}

Since 1985 data on all infants who have received surfactant therapy for severe RDS in our unit have been recorded on a computer database. The first 19 babies were enrolled in the Collaborative European Multicentre study of surfactant replacement therapy for severe RDS. ${ }^{1}$ This extensive database has included all infants receiving surfactant therapy since the conclusion of this trial.

We used Curosurf a natural surfactant derived from porcine lung which was given in a dose of $200 \mathrm{mg} / \mathrm{kg}$ of phospholipid. All babies had intermittent positive pressure ventilation (IPPV) and were receiving more than $40-60 \% \mathrm{O}_{2}$.

Because of the proved beneficial effects of surfactant therapy we were unable to use matched controls with severe RDS so we have used age and birthweight matched comparisons who did not receive surfactant therapy from the same time period.

All infants studied were managed in the neonatal intensive care unit of the Royal Maternity Hospital, Belfast which is a regional intensive care unit. All infants were examined by a paediatric ophthalmologist using indirect ophthalmoscopy following pupillary dilatation with phenylephrine $2 \cdot 5 \%$ and cyclopentolate $1 \%$ eye drops. Their findings were documented in accordance with the International Classification of ROP, ${ }^{3}$ that is, stage 1: a demarcation line; stage 2: ridge formation; stage 3: a ridge with extraretinal fibrovascular proliferation; stage 4 : partial retinal detachment; stage 5: total retinal detachment. Threshold disease was defined as at least 5 contiguous clock hours or 8 cumulative clock hours of stage 3 ROP in zone 1 or 2 in the presence of 'plus' disease (dilatation and tortuosity of the posterior retinal vessels). The infants were first examined at the equivalent of 32 weeks post-conceptional age and thereafter 2-weekly until 36 weeks and regression of any ROP was noted. If ROP was found then examination was weekly unless stage 2 'plus' or stage 3 was reached in which case examination was more frequently. Details of these examinations were retrieved retrospectively from the infants' records and added to the database.

\section{Results}

Seventy six babies of less than $1500 \mathrm{~g}$ birth weight and less than 31 weeks' gestational age were treated with surfactant. Fifty nine of these survived to 32 weeks' post-conceptional age 
allowing at least one eye examination. The control group consisted of 90 gestational age and birthweight matched babies who survived during the period of our study. These babies did not have severe RDS and did not receive surfactant. The characteristics of the groups are shown in Table 1 .

Acute ROP developed in $15(25.4 \%)$ of the surfactant group and $16(17 \cdot 8 \%)$ of the comparisons. The distributions of ROP for birth weight and gestational age are shown in Tables 2 and 3. Threshold disease or greater was reached one $(1 \cdot 7 \%)$ of the surfactant group and $7(7 \cdot 8 \%)$ of the comparisons; this difference was not significant.

Twenty five of the surfactant group were less than $1000 \mathrm{~g}$ birth weight with mean (SD) 834 (127) $\mathrm{g}$ and gestational age $26 \cdot 3(1 \cdot 2)$ weeks. This compared with 43 in the control group with a mean birth weight of 823 (166) $\mathrm{g}$ and gestational age $27 \cdot 1(2 \cdot 0)$ weeks. In these groups one $(4 \cdot 0 \%)$ of the surfactant group and seven $(16 \cdot 3 \%)$ of the controls developed threshold or greater ROP; again this difference was not significant.

In the full surfactant group six babies including the single baby with stage 4 disease died of late complications after 32 weeks post-conceptional age. Likewise three of the comparison group died late with stages 2,3 , and 4 disease respectively.

\section{Discussion}

RDS is a common problem in the preterm neonate. Sixty five per cent of those babies of less than $1500 \mathrm{~g}$ develop RDS increasing to $80 \%$ of those less than $1000 \mathrm{~g}$ birth weight. ${ }^{4}$ In this group hypoxia, hypercarbia, respiratory, and metabolic acidosis are commonplace. All these factors have been shown to be significantly associated with the development of acute ROP. ${ }^{567}$ Many individual risk factors have been implicated in the genesis of ROP suggesting that the common thread is neonatal illness with disturbed homeostasis upsetting the delicately balanced process of retinal development. ${ }^{7}$ Progression of ROP to advanced disease also seems to be largely determined by the severity of the early insult to the immature retina and is less influenced by prolonged or subsequent adverse effects. ${ }^{6}$ Surfactant therapy in the first 48 hours of life has been shown to have been a significant advance in improving the survival rate of these particularly sick neonates. ${ }^{12}$

In treating the neonate with respiratory problems an arterial oxygen tension of $8-12 \mathrm{kPa}$ is considered optimal. Surfactant therapy can cause an initial surge in oxygenation to levels of $20-30 \mathrm{kPa}$ which is now closely monitored by pulse oximetry so that supplemental oxygen is reduced optimising tissue oxygenation and so avoiding the risks of hyperoxaemia.

The population of surfactant treated babies described in this study had severe RDS and were treated in a 'rescue' rather than a prophylactic trial. The comparison group did not have severe RDS and therefore were generally a less sick population. The results should be viewed with this disparity in mind so that the original hypothesis that there may be an increased risk of
Table 1 Characteristics of surfactant treated and comparison babies surviving to examination

\begin{tabular}{|c|c|c|}
\hline & $\begin{array}{l}\text { Surfactant treated } \\
(n=59)\end{array}$ & $\begin{array}{l}\text { Control } \\
(n=90)\end{array}$ \\
\hline \multicolumn{3}{|l|}{ Birth weight (g) } \\
\hline $\operatorname{Mean}(\mathrm{SD})$ & $1046(232)$ & $1053(269)$ \\
\hline Gestational age (weeks) & & \\
\hline Mean $(\mathrm{SD})$ & $27 \cdot 5(1 \cdot 7)$ & $27 \cdot 8(1 \cdot 9)$ \\
\hline $\begin{array}{l}\text { Male } \\
\text { No (\%) }\end{array}$ & $38(64)$ & $39(43)$ \\
\hline $\begin{array}{c}\operatorname{No}(\%) \\
\operatorname{Max} \mathrm{FiO}_{2}^{\star}\end{array}$ & $38(64)$ & $39(43)$ \\
\hline $\begin{array}{l}\text { Mean (SD) } \\
\text { IPPV† }\end{array}$ & $0 \cdot 76(0 \cdot 15)$ & $0.56(0.25)$ \\
\hline No(\%) & $59(100)$ & $62(69)$ \\
\hline $\begin{array}{c}\text { Duration of } \mathrm{O}_{2}(\mathrm{~h}) \\
\text { Median (range) }\end{array}$ & $\begin{array}{l}1008 \\
(172-5424)\end{array}$ & $\begin{array}{l}360 \\
(0-5208)\end{array}$ \\
\hline \multicolumn{3}{|l|}{ Mortality } \\
\hline No(\%) & $6(10)$ & $3(3)$ \\
\hline
\end{tabular}

^Fraction of inspired oxygen.

†Intermittent positive pressure ventilation.

Table 2 Distribution of ROP by birth weight in $(A)$ surfactant treated babies and $(B)$ comparisons

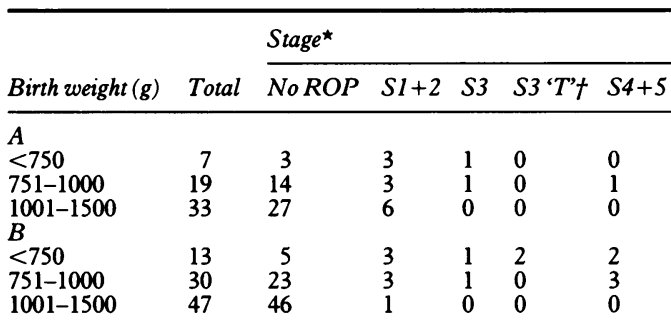

^International classification of ROP.

†Threshold.

Table 3 Distribution of ROP by gestational age in $(A)$ surfactant treated babies and $(B)$ comparisons

\begin{tabular}{lllllll}
\hline \multirow{2}{*}{$\begin{array}{l}\text { Gestational age } \\
\text { (weeks) }\end{array}$} & Total & No ROP & $S 1+2$ & $S 3$ & Stage 'T't & $S 4+5$ \\
\cline { 3 - 7 } & & & & & \\
\hline$A$ & 31 & 19 & 9 & 2 & 0 & 1 \\
$23-27$ & 28 & 25 & 3 & 0 & 0 & 0 \\
$28-31$ & 53 & 37 & 7 & 2 & 2 & 5 \\
$B$ & 37 & 37 & 0 & 0 & 0 & 0 \\
$23-27$ & $28-31$ & &
\end{tabular}

¿International classification of ROP

†Threshold.

ROP in the sicker population requiring surfactant treatment was not sustained.

Estimates of the incidence of ROP in similar age and birthweight matched populations vary from $3-50 \% .{ }^{89}$ Our rates of $25.9 \%$ in the surfactant group and $17.8 \%$ in the comparisons are therefore compatible. It is perhaps more relevant to study how many infants progress to threshold disease as this is the group in whom intervention with cryopexy is indicated. ${ }^{10}$ Only $1.7 \%$ of the surfactant group and $7 \cdot 8 \%$ of comparisons reached threshold disease or greater and in the most at-risk population of less than $1000 \mathrm{~g}$ birth weight the incidence is $4 \%$ in the surfactant group and $16.3 \%$ in the comparisons. These differences are not significant but they confirm that despite being a sicker more at risk population babies receiving surfactant are not at increased risk of ROP.

Kalina has recently highlighted the concern that the increased survival of low birthweight infants and their prolonged oxygen dependence may increase their risk of ROP. ${ }^{11}$ It is our view that decreasing the severity of the early insult will decrease the risk of severe ROP. The value of surfactant therapy is not only in improving the 
survival of low birthweight infants but also decreasing the risk of severe ROP.

By improving oxygenation and stabilising infants' homeostasis in this early critical period subsequent prolonged oxygen dependence may not be as significant a factor in the genesis of ROP. Surfactant replacement therapy may have an important role in achieving this early stability. Further investigation is warranted to increase the numbers of infants treated with different types of surfactant and examined for ROP so that any potential beneficial effect can be confirmed.

1 Collaborative European Multicenter Study Group. Surfactant replacement therapy for severe neonatal respiratory distress syndrome: an international randomized clinical trial. syndrome: an international
Pediatrics 1988; 82: 683-91.

2 Dunn MS, Shennan AT, Hoskins EM, Enhorning G. Twoyear follow up of infants enrolled in a randomized trial of surfactant replacement therapy for prevention of neonatal respiratory distress syndrome. Pediatrics $1988 ; 82$ : 543-7.

3 Committee for the classification of ROP. An international classification of ROP. Pediatrics 1984; 74: 127-33.

4 McClure G, Halliday H, Thompson W. Respiratory distress syndrome. In: McClure G, Halliday H, Thompson W, (eds).

5 Saugsted OD. Oxygen toxicity in the neonatal period. Acta Paediatr Scand 1990; 79: 881-92.

6 Prendiville A, Schulenberg WE. Clinical factors associated with retinopathy of prematurity. Arch Dis Child 1988; 63: $522-7$

7 Avery GB, Glass P. Retinopathy of prematurity: what causes it? Clin Perinatol 1988; 15: 917-28.

8 Yu VYH, Hockham DM, Nave JRM. Retrolental fibroplasia: a controlled study of 4 years experience in a neonata intensive care unit. Arch Dis Child 1982; 57: 247-52.

$9 \mathrm{Ng} \mathrm{YK}$, Fielder AR, Shaw DE, Levene MI. Epidemiology of retinopathy of prematurity. Lancet 1988; ii: 1235-8.

10 Cryotherapy for Retinopathy of Prematurity Study Group Multicentre Trial of Cryotherapy for Retinopathy of Prematurity; Preliminary Results. Arch Ophthalmol 1988, 106: turity;

11 Kalina RE. Treatment of retinal detachment due to retinopathy of prematurity, documented disappointment. Ophthalpathy of prematurity,
mology $1991 ; 98: 3-4$. 